\title{
Interictal cytokine levels were correlated to seizure severity of epileptic patients: a retrospective study on 1218 epileptic patients
}

\author{
Ye Wang ${ }^{1}$, Desheng Wang ${ }^{1}$ and Dawen Guo ${ }^{2^{*}}$
}

\begin{abstract}
Background: Many aspects on the correlation between epilepsy and cytokine levels were unclear. This study aims to investigate the correlations between cytokine levels and severe epilepsy.

Methods: Totally 1218 epileptic patients were grouped by types of epilepsy: TLE (temporal lobe epilepsy, $n=409$ ), XLE (extra-temporal lobe epilepsy, $n=290$ ) and IGE (idiopathic generalized epilepsy, $n=519$ ). Two hundred healthy volunteers were as controls. Clinical findings and levels of 14 serum and CSF cytokines and 6 STAT members were collected, measured and analyzed.

Results: Analysis showed no differences in interictal cytokine levels among patients from TLE, XLE and IGE groups. Interictal serum levels of IL-1 b, IL-1Ra, IL-6, IL-8, IFNY, IFN 3 and IL-17a were associated with seizure severity of epileptic patients, measured by seizure frequency, VA score or NHS3. Multivariate regression analysis indicated that interictal concentrations of serum IL-6, IFNy, IL-17a, IFN 3 , and CSF IL-6, IL-17a, IFN $\lambda 3$ were significant biomarkers for patients with severe epilepsy. mRNA levels of IL-6, IFNy, IL-17a, and IFN 3 were elevated in different types of epilepsy. Activation of all STATs was elevated in epilepsy, and STAT3 was activated 9-fold in average, which was the highest among all STATs.

Conclusions: Interictal serum IL-6, IFNy, IL-17a, IFN $\lambda$ 3, and CSF IL-6, IL-17a, IFN $\lambda 3$ could be used as potential biomarkers for severe epilepsy. Activation of STATs, especially STAT3, was important in epilepsy. Our findings pointed out crucial roles of cytokine levels in epilepsy.
\end{abstract}

Keywords: Biomarker, Cytokine, Epilepsy, Seizure, Disease severity

\section{Background}

Cytokines and chemokines are important mediators in many physiological and pathological modulations including nervous system development, bidirectional signal transduction between central and peripheral nerve systems, cognitive processes, and etc. $[1,2]$. Under most physiological conditions, cytokine levels are low, but they could increase manifold up to hundreds of times their basal concentrations in pathological conditions. It has been reported that adult brain cells express cytokines

\footnotetext{
*Correspondence: Dawen_Guo@163.com

${ }^{2}$ Department of Clinical Laboratory, First Affiliated Hospital of Harbin Medical University, Harbin, Heilongjiang 150001, Peoples' Republic of China

Full list of author information is available at the end of the article
}

such as IL-1b, IL-6, IL-8, IL-10, IL-12, IL-15, TNF, CCL2, CCL3 and CCL4 [3]. New cytokines are being identified in CNS (central nerve system).

Regulations of expression and secretion of cytokines and their receptors have been described in patients with epilepsy, in addition to animal models of epilepsy $[4,5]$. For example, serum IL-1b, IL-1Ra, IL-2, IL-4, IL-6, IL-8, IFN $\gamma$, and IL-17 concentrations were observed to be elevated in patients with epilepsy [4-8]. Elevated IL-6 and IL-17 levels in CSF (cerebrospinal fluid) were also reported in publications [8-10]. In addition, both IL-6 and CCL2 are elevated in the temporal cortex of pediatric patients from families with epilepsy history [11]. A recent case-control study indicated that after blocking IL-6R with the monoclonal antibody, tocilizumab, stable 
remission of epileptic symptoms could be achieved [12]. Additional reports showed that IL-4, IL-8 and IL-17 concentrations may be correlated to seizure frequency and severity [7-9, 13]. All above evidences suggest key roles of cytokines in diagnosis and treatment of epilepsy. But the definite correlations between above cytokines and different types of epilepsy, and with seizure severity still need to be investigated.

The objective of this study was to analyze the clinical and laboratory data of a group of epileptic patients, and evaluate the correlations between interictal cytokine concentrations and seizure severity in different types of epilepsy. This study aims to identify serum markers of disease severity in order to facilitate more accurate diagnosis of severe epilepsy, so that prophylactic measures can be taken.

\section{Methods}

\section{Study population}

Our study population consisted of 1218 interictal patients with symptomatic epilepsy who were treated at our institution from January 2009 to February 2015. Exclusion criteria include a history of autoimmune diseases, allergic response, immune deficiency disorder, diabetes, psychiatric illness, malignancy, severe cognitive impairment, or a systemic or central nervous system (CNS) infection 2 weeks before sample collection. Two hundred age- and sex-matched healthy volunteers were involved in this study.

Epilepsy was diagnosed by at least two licensed and experienced neurologists according to the 2006 International League Against Epilepsy (ILAE) Classification [14]. Seizure frequency was evaluated by using seizure diaries and seizure severity was by using the National Hospital Seizure Severity Scale (NHS3) and the Veterans Administration Seizures Frequency and Severity Rating Scale score (VA score) [15]. TLE (temporal lobe epilepsy), XLE (extra-temporal lobe epilepsy) and IGE (idiopathic generalized epilepsy) were diagnosed based on medical history, electro-clinical findings (including seizure semiology and EEG/video-EEG) and neuro-imaging [10]. A high-resolution 1.5 Tesla magnetic resonance imaging (MRI) scan of the brain with a specific epilepsy protocol was obtained to define the etiology, which was classified as normal and abnormal.

\section{Data source}

All of the interictal parameters included in the investigation were collected at day 7 from the last seizure attack. The collected clinical parameters included demographic characteristics (age and sex), clinical parameters (signs and symptoms), laboratory values (hematologic, biochemical and microbiological findings), radiologic data, epileptic duration, seizure frequency per month in the past year, and number of epileptic drugs.

The Harbin Medical University First Hospital Ethics Committee approved the study, and all involved healthy volunteers and patients gave written informed consent for their clinical data and samples (blood, serum and CSF) to be used in this study. Human experimentation guidelines of PR.China were followed in the conduct of this research.

\section{Cytokine level determination}

Interictal samples were collected at day 7 from the last seizure attack. The plasma was harvested within $30 \mathrm{~min}$ at $37{ }^{\circ} \mathrm{C}$ of venipuncture from EDTA-anticoagulated blood samples and stored at $-80{ }^{\circ} \mathrm{C}$ for subsequent cytokine analysis. The concentrations of IL-2, IL-4, IL-6, IL-8, IL-10, IFN $\gamma$, GM-CSF, TNF $\alpha$ (Bio-Rad, USA), IL17a (PeproTech, Rocky Hill, NJ, USA), IL-1 $\beta$ (Bender MedSystems, Vienna, Austria), IL1Ra (Cytoscreen, Biosource, Belgium), IFN $\lambda 1$, IFN $\lambda 2$, IFN $\lambda 3$, IFN $\lambda 4$ (eBioscience, CA, USA), and IL-23 (Invitrogen, Carlsbad, CA, USA) were measured by ELISA according to manufacturers' instruction [16-20]. CSF concentrations of IL-6, IFN $\gamma$, IFN $\lambda 3$ and IL-17a were measured using human cytoline/chemokine MILLIplex kits (Millipore Corp, Billerica, MA, USA) [21]. ELISAs were performed in duplicate.

\section{Statistical analysis}

Averages of numerical variables were presented as $\bar{\chi} \pm$ SD. Differences were compared by Chi square test for categorical data and unpaired Student's $t$ test for continuous normally distributed data (tested by Wilk-Shapiro test). Cytokine concentrations were compared by MannWhitney $U$ test. Correlation between cytokine levels and seizure frequency/severity was analyzed by Spearman correlation and multivariate linear regression analysis. In multivariate regression analysis, variables with a $\mathrm{p}$-value less than 0.05 were included in the model, and all of the continuous data had skewed distribution and were logarithmically transformed to fit normal distribution. All analyses were performed by SPSS software (version 11.0). Statistical data in multivariate regression analysis were shown with $\mathrm{P}$ value $<0.05$ or $<0.01$ to be considered as statistically significant.

\section{Results}

\section{Patient characteristics}

The demographic and clinical data of 1218 patients with different types of epilepsy were collected and summarized in Table 1 . The average duration of their hospital stay was $13.77 \pm 11.22$ days. All patients were recovered and discharged, and no one died. The epileptic patients 
Table 1 Clinical characteristic of epileptic patients

\begin{tabular}{|c|c|c|c|}
\hline Epilepsy syndrome & TLE & XLE & IGE \\
\hline$n$ & 409 & 290 & 519 \\
\hline Female/male & $90 / 319$ & $51 / 239$ & $110 / 409$ \\
\hline Age (mean $\pm S D$, years) & $33.2 \pm 12.4$ & $31.0 \pm 10.9$ & $30.8 \pm 10.8$ \\
\hline $\begin{array}{l}\text { Epilepsy duration (mean } \pm \text { SD, } \\
\text { years) }\end{array}$ & $15.1 \pm 9.8$ & $19.2 \pm 15.2$ & $10.9 \pm 11.2$ \\
\hline $\begin{array}{l}\text { Seizure frequency (mean } \pm \text { SD, } \\
\text { seizure/month) }\end{array}$ & $10.0 \pm 12.4$ & $19.3 \pm 17.3$ & $15.5 \pm 11.3$ \\
\hline \multicolumn{4}{|l|}{ Brain MRI (n, \%) } \\
\hline Normal & $316(77.3)$ & $190(65.5)$ & $519(100)$ \\
\hline Abnormal & $93(22.7)$ & $100(34.5)$ & 0 \\
\hline \multicolumn{4}{|l|}{ Side of epilepsy (n, \%) } \\
\hline Left & $119(29.1)$ & $78(26.9)$ & $136(26.2)$ \\
\hline Right & $192(46.9)$ & $76(26.2)$ & $166(32.0)$ \\
\hline Unidentified & $98(24.0)$ & $136(46.9)$ & $217(41.8)$ \\
\hline \multicolumn{4}{|l|}{ Anti-epileptic drugs (n, \%) } \\
\hline None & $7(1.7)$ & $5(1.7)$ & $7(1.4)$ \\
\hline Mono-drug & $37(9.0)$ & $39(13.4)$ & $76(14.7)$ \\
\hline Poly-drug & $365(89.2)$ & $246(84.9)$ & $436(84.0)$ \\
\hline Refractory epilepsy (n, \%) & 377 (92.2) & $268(92.4)$ & $468(90.1)$ \\
\hline
\end{tabular}

Refractory epilepsy was defined as $>2$ seizures/month during last year under pharmacologically treatment

VA score Veterans Administration Seizures Frequency and Severity Rating Scale score, NHS3 National Hospital Seizure Severity Scale, TLE temporal lobe epilepsy, $X L E$ extra-temporal lobe epilepsy, IGE idiopathic generalized epilepsy

Table 2 Laboratory findings

\begin{tabular}{lccc}
\hline & TLE $(\mathbf{n}=\mathbf{4 0 9})$ & XLE $(\mathbf{n}=\mathbf{2 9 0})$ & IGE $(\mathbf{n}=\mathbf{5 1 9})$ \\
\hline GLU $(\mathrm{mmol} / \mathrm{L})$ & $7.3 \pm 2.4$ & $6.9 \pm 3.3$ & $7.6 \pm 4.1$ \\
WBC $\left(10^{9} / \mathrm{L}\right)$ & $9.3 \pm 4.5$ & $10.4 \pm 3.2$ & $9.2 \pm 4.7$ \\
Neutrophils $(\%)$ & $57.7 \pm 21.6$ & $57.1 \pm 22.8$ & $60.5 \pm 25.7$ \\
Lymphocytes $(\%)$ & $39.6 \pm 15.6$ & $37.2 \pm 20.5$ & $40.0 \pm 16.3$ \\
HB (g/dL) & $132.2 \pm 22.3$ & $118.9 \pm 32.1$ & $119.4 \pm 33.0$ \\
$\mathrm{PLT}\left(10^{9} / \mathrm{L}\right)$ & $301.2 \pm 103.4$ & $290.1 \pm 111.1$ & $288.9 \pm 143.2$ \\
ALT $(\mathrm{IU} / \mathrm{L})$ & $29.6 \pm 25.3$ & $21.2 \pm 31.7$ & $27.7 \pm 25.7$ \\
$\mathrm{AST}(\mathrm{IU} / \mathrm{L})$ & $32.5 \pm 26.2$ & $34.9 \pm 28.2$ & $31.5 \pm 26.5$ \\
$\mathrm{CK}-\mathrm{MB}(\mathrm{IU} / \mathrm{L})$ & $17.2 \pm 28.3$ & $19.3 \pm 23.7$ & $17.3 \pm 31.1$ \\
$\mathrm{CRP}(\mathrm{mg} / \mathrm{L})$ & $3.2 \pm 4.2$ & $3.7 \pm 4.9$ & $3.3 \pm 3.4$ \\
$\mathrm{LDH}(\mathrm{U} / \mathrm{L})$ & $254.1 \pm 73.2$ & $253.2 \pm 76.4$ & $243.6 \pm 70.0$ \\
$\mathrm{~K}(\mathrm{mmol} / \mathrm{L})$ & $4.1 \pm 1.3$ & $4.1 \pm 1.8$ & $4.3 \pm 1.9$ \\
$\mathrm{Na}(\mathrm{mmol} / \mathrm{L})$ & $134.8 \pm 3.8$ & $135.3 \pm 3.3$ & $136.2 \pm 4.0$ \\
$\mathrm{CL}(\mathrm{mmol} / \mathrm{L})$ & $102.3 \pm 39.8$ & $109.2 \pm 38.0$ & $101.3 \pm 38.3$
\end{tabular}

GLU blood glucose, $L Y M$ percentage of lymphocytes, $A L T$ alanine aminotransferase, $C L$ blood chlorine, WBC white blood cell counts, $C K$ creatine kinase, $C K-M B$ creatine kinase-MB, CRP C-reactive protein, $L D H$ Lactate dehydrogenase, $T L E$ temporal lobe epilepsy, XLE extra-temporal lobe epilepsy, IGE idiopathic generalized epilepsy

involved in this study were categorized into three groups (TLE $(\mathrm{n}=409)$, XLE $(\mathrm{n}=290)$, and IGE $(\mathrm{n}=519)$ ). Except for brain MRI, there were no statistic differences between groups in term of clinical characteristics (all $\mathrm{P}$ values $>0.05$, Table 1$)$. Laboratory findings of epileptic patients in each study group were shown in Table 2. No significant differences were found between groups (all $\mathrm{P}$ values $>0.05$ ).

\section{Correlation between interictal cytokine levels and different types of epilepsy}

To discover potential serum biomarkers for differentiate TLE, XLE and IGE, we tested 14 interictal cytokine concentrations (IL-1b, IL-1Ra, IL-2, IL-4, IL-6, IL-8, IL-10, IFN $\gamma$, IL-17a, IFN $\lambda 1$, IFN $\lambda 2$, IFN $\lambda 3$, IFN $\lambda 4$, and IL-23). The levels of tested cytokines in patients with different types of epilepsy were analyzed. Unfortunately, none of these cytokine concentrations showed any statistical significance between different epileptic groups (all $\mathrm{P}>0.05$ ).

\section{Correlation between interictal serum cytokine levels and seizure severity}

Next, we tried to investigate whether interictal cytokine levels could be used as markers to indicate seizure severity in patients with different types of epilepsy. Seizure frequency, VA score, and NHS3 were used as seizure severity scales. Table 3 demonstrated statistical analysis results on each cytokine. If seizure frequency was used for seizure severity, then levels of IL-6, IL- 8 and IL-17a were significant biomarkers in all three types of epilepsy. IL-1Ra was for TLE and XLE ( $P=0.041$ and 0.032 , respectively), IFN $\gamma$, IFN $\lambda 2$ and IFN $\lambda 4$ were for $\mathrm{XLE}(\mathrm{P}=0.008,0.004$ and 0.022$)$, and IFN $\lambda 3$ for IGE $(\mathrm{P}=0.003)$. If VA score was applied, IL-1Ra, IL-6, IFN $\gamma$, IFN $\lambda 3$ and IL-17a were severity markers in all types of epilepsy. IFN $\lambda 2$ and IFN $\lambda 3$ were for TLE $(P=0.042$ and 0.008$)$. IL-1b, IL-8, IFN $\lambda 1$ and IFN $\lambda 3$ were for XLE $(\mathrm{P}=0.033,0.005,0.006$, and 0.010 respectively). If NHS3 was used, IL-6, IFN $\gamma$ and IFN $\lambda 3$ were good markers in all types of epilepsy. IL-1Ra, IL-8 and IL-17a were for TLE $(\mathrm{P}=0.020,0.012$ and 0.021 , respectively), IL-17a and all IFN $\lambda$ s were for XLE $(\mathrm{P}=0.049,0.025,0.049,<0.001$ and $0.006)$, and IL-1Ra, IL-8, IFN $\lambda 1$, and IFN $\lambda 4$ were for IGE $(\mathrm{P}=0.009,0.005,0.011$ and 0.043 respectively). Among all cytokine concentrations, only IL-6 level was correlated to all three severity scaling systems in all three types of epilepsy. IFN $\lambda 3$ was also good for all scaling systems in all types of epilepsy, except for frequency in TLE and XLE.

Furthermore, multivariate regression analysis revealed that interictal IL-6 concentration was positively related to seizure frequency in TLE and IGE $(P=0.041$ and 0.002 , respectively), VA score in IGE $(\mathrm{P}<0.001)$, and NHS3 in XLE $(\mathrm{P}=0.005)$. IFN $\gamma$ level was positively linked to VA score in XLE $(P=0.015)$, and NHS3 in TLE $(\mathrm{P}=0.023)$. IL-17a level was positively associated with VA score in TLE and IGE $(\mathrm{P}=0.010$ and 0.022 , 
Table 3 Correlation analysis between cytokine levels and disease severity in different types of epilepsy

\begin{tabular}{|c|c|c|c|c|c|c|c|c|c|}
\hline & \multicolumn{3}{|c|}{ TLE $(n=409)$} & \multicolumn{3}{|c|}{ XLE $(n=290)$} & \multicolumn{3}{|c|}{ IGE $(n=519)$} \\
\hline & Freq & VA & NHS3 & Freq & VA & NHS3 & Freq & VA & NHS3 \\
\hline IL-1b & 0.058 & 0.098 & 0.075 & 0.069 & $0.033^{*}$ & 0.141 & 0.069 & 0.091 & 0.143 \\
\hline IL-1Ra & $0.041^{*}$ & $0.004^{* *}$ & $0.020^{*}$ & $0.032^{*}$ & $0.021^{*}$ & 0.078 & 0.059 & $0.005^{* *}$ & $0.009^{* *}$ \\
\hline $\mathrm{IL}-2$ & 0.095 & 0.121 & 0.119 & 0.077 & 0.089 & 0.083 & 0.132 & 0.244 & 0.097 \\
\hline $\mid \mathrm{L}-4$ & 0.249 & 0.192 & 0.104 & 0.193 & 0.087 & 0.102 & 0.201 & 0.167 & 0.131 \\
\hline IL-6 & $0.002^{* *}$ & $0.045^{*}$ & $0.005^{* *}$ & $0.003^{* *}$ & $0.042^{*}$ & $<0.001^{* *}$ & $0.001^{* *}$ & $<0.001^{* *}$ & $0.003^{* *}$ \\
\hline IL-8 & $0.007^{* *}$ & 0.077 & $0.012^{*}$ & $0.001^{* *}$ & $0.005^{* *}$ & 0.083 & $0.031^{*}$ & 0.051 & $0.005^{* *}$ \\
\hline $\mathrm{IL}-10$ & 0.210 & 0.088 & 0.089 & 0.192 & 0.094 & 0.078 & 0.201 & 0.194 & 0.076 \\
\hline IFNY & 0.081 & $0.011^{*}$ & $0.008^{* *}$ & $0.008^{* *}$ & $0.004^{* *}$ & $0.034^{*}$ & 0.066 & $0.018^{*}$ & $0.010^{*}$ \\
\hline IFN $\lambda 1$ & 0.091 & 0.112 & 0.077 & $0.004^{* *}$ & $0.006^{* *}$ & $0.025^{*}$ & 0.092 & 0.082 & $0.011^{*}$ \\
\hline IFN $\lambda 2$ & $0.022^{*}$ & $0.042^{*}$ & 0.121 & 0.394 & 0.112 & $0.049^{*}$ & 0.079 & 0.099 & 0.245 \\
\hline $\mathrm{IFN} \lambda 3$ & 0.101 & $0.008^{* *}$ & $<0.001^{* *}$ & 0.058 & $0.010^{*}$ & $<0.001^{* *}$ & $0.003^{* *}$ & $0.045^{*}$ & $0.004^{* *}$ \\
\hline $\mathrm{IFN} \lambda 4$ & 0.100 & 0.192 & 0.492 & $0.022^{*}$ & 0.051 & $0.006^{* *}$ & 0.148 & 0.051 & $0.043^{*}$ \\
\hline IL-17a & $0.001^{* *}$ & $<0.001^{* *}$ & $0.021^{*}$ & $0.023^{*}$ & $0.011^{*}$ & $0.049^{*}$ & $0.036^{*}$ & $0.001^{* *}$ & 0.078 \\
\hline IL-23 & 0.172 & 0.099 & 0.221 & 0.255 & 0.301 & 0.175 & 0.141 & 0.187 & 0.251 \\
\hline
\end{tabular}

Freq seizure frequency per month, VA score Veterans Administration Seizures Frequency and Severity Rating Scale score, NHS3 National Hospital Seizure Severity Scale, TLE temporal lobe epilepsy, XLE extra-temporal lobe epilepsy, IGE idiopathic generalized epilepsy

$* P<0.05,{ }^{* *} P<0.01$

Table 4 Independent biomarkers for severe seizures

\begin{tabular}{|c|c|c|c|c|c|c|c|c|c|}
\hline & TLE ( $r$ & & & XLE ( $r$ & & & IGE (n & & \\
\hline & Freq & VA & NHS3 & Freq & VA & NHS3 & Freq & VA & NHS3 \\
\hline IL-6 & 0.041 & & & & & $0.005^{*}$ & $0.002^{*}$ & $<0.001^{*}$ & \\
\hline IFNY & & & 0.023 & & 0.015 & & & & \\
\hline IFN $\lambda 3$ & & & 0.019 & & & & 0.034 & & 0.022 \\
\hline IL-17a & & 0.010 & & & & & & 0.022 & \\
\hline
\end{tabular}

Freq seizure frequency per month, VA score Veterans Administration Seizures Frequency and Severity Rating Scale score, NHS3 National Hospital Seizure Severity Scale, $T L E$ temporal lobe epilepsy, XLE extra-temporal lobe epilepsy, IGE idiopathic generalized epilepsy

* $\mathrm{P}<0.01$

respectively). IFN $\lambda 3$ concentration was positively linked to NHS3 in TLE and IGE ( $\mathrm{P}=0.019$ and 0.022$)$, and seizure frequency in IGE $(\mathrm{P}=0.034)$ (Table 4$)$. The overall data of statistical analysis on correlations between seizure severity and cytokine levels in TLE, XLE and IGE were shown graphically in Fig. 1 . If $P<0.01$ was considered significant, then only IL- 6 concentration was positively linked to NHS3 in XLE $(P=0.005)$, seizure frequency and VA score in IGE $(\mathrm{P}=0.002$ and $<0.001$, respectively).

The mRNA concentrations of 14 tested cytokines were evaluated, and the data on IL-6, IL-17a, IFNY and IFN $\lambda 3$ were shown in Fig. 2, since these four cytokines were identified in the multivariate analysis (Table 4). The mRNA levels of all these four cytokines were correlated to all three types of epilepsy. No difference was observed between types of epilepsy (all $\mathrm{P}>0.05)$.

\section{Correlation between interictal cytokine levels and} the time to next seizure episodes

Inflammation status may have an impact on the time to next seizure episodes, and cytokine levels are known biomarkers for inflammation intensity. So we analyzed the correlation between interictal serum cytokine levels and the time (days) to the next seizure episode since the study time point. All patients were followed up for 6 months. Data were shown in Table 5. IL-6 level was an independent biomarker for the time to next seizure episode in XLE $(\mathrm{P}=0.002), \mathrm{IFN} \gamma$ level was an independent biomarker in TLE $(\mathrm{P}=0.041)$, IFN $\lambda 3$ was in TLE and XLE $(\mathrm{P}=0.002$ and 0.032), and IL-17a was in TLE and XLE $(P=0.009$ and $<0.001$, respectively). If $\mathrm{P}<0.01$ was considered statistically significant, then only IFN $\lambda 3$ and IL-17a levels in TLE ( $\mathrm{P}=0.002$ and 0.009 , respectively), IL-6 and IL-17a in XLE ( $\mathrm{P}=0.002$ and $<0.001$, respectively) were independent biomarkers. 


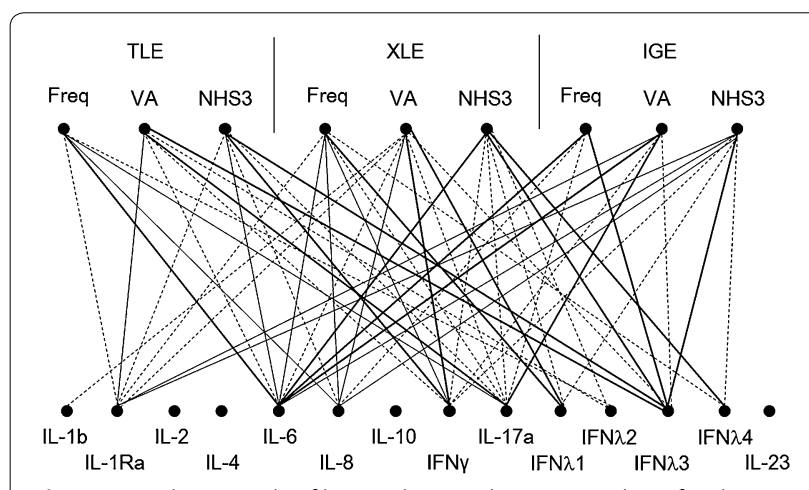

Fig. 1 Correlation web of biomarkers and severity indices for three types of epilepsies. The cross-correlation of cytokine levels with seizure indices for three types of epilepsies was shown in the form of directed correlation web. The line thickness indicates the significance of the correlations. Bold line The statistical correlation is $<0.05$ in multivariate analysis; Thin line The statistical correlation is $<0.01$ in univariate analysis; Dash line: The statistical correlation is $<0.01$ in univariate analysis. TLE temporal lobe epilepsy, XLE extra-temporal lobe epilepsy, and IGE idiopathic generalized epilepsy

\section{Correlation between interictal CSF cytokine levels and seizure severity}

To further evaluate the association between cytokine levels and seizure severity, concentrations of CSF IL-6, IFN $\gamma$, IFN $\lambda 3$ and IL-17a were tested on 150 patients selected from our different epileptic groups, respectively (50 of which were with TLE, XLE and IGE, respectively). These patients were randomly selected from the 1218 epileptic patients in this study, and their demographic and clinical features were matched between groups. Statistical analysis demonstrated that CSF IL-6 concentration was an independent markers for XLE if NHS3 was used for seizure severity $(\mathrm{P}=0.007)$. CSF IL-17a was an independent marker for TLE and IGE if VA score was used $(\mathrm{P}=0.039$ and 0.044 , respectively). CSF IFN $\lambda 3$ was an independent marker for TLE and NHS3 if NHS3 was used ( $\mathrm{P}=0.022$ and 0.012 , respectively). If $\mathrm{P}<0.01$ was considered statistically significant, then only IL- 6 in XLE could be recognized as an independent biomarker (Table 6). By univariate analysis, CSF IFN $\gamma$ level was associated with TLE if VA or NHS3 ( $\mathrm{P}=0.045$ and 0.033 , respectively) was applied, but failed to enter the multivariate regression model.

\section{Activation of STAT family members was elevated in epilepsy}

STATs are key signaling mediators induced by most interleukins and interferons [22]. The concentrations of activated all 6 STAT family members were evaluated in blood PBMCs of patients with different types of epilepsy. We found that activation of all tested STATs was significantly elevated in all three types of epilepsy. Among all STAT members, STAT3 activation level was increased ninefold in average, much higher than other STAT members (3-5 fold), indicating potential critical role of STAT3 in epilepsy (Fig. 3).

\section{Discussion}

Vezzani et al. has well documented that CNS inflammatory processes may play crucial roles in the pathophysiology of seizures and epilepsy [23]. Cytokines are key mediators of both pro- and anti-inflammatory processes. Previous studies have implicated various cytokines in epilepsy $[6-8,24]$. Here we tried to investigate the association of interictal concentrations of 10 cytokines to seizure severity in three types of epilepsy (TLE, XLE and IGE). Our data demonstrated 6 potential biomarkers and 3 independent biomarkers for severe epilepsy. No significant differences were observed among different types of epilepsy.

Prior publications have demonstrated the correlation between concentrations of certain cytokines and epilepsy. IL-6 is a pleiotropic cytokine expressed in various cell types and tissues [25]. Its serum concentration is elevated in the settings of many neurological disorders such as Alzheimer's disease, trauma and meningitis [26-28]. Previous publications have indicated elevated IL- 6 level after focal and generalized seizures in patients with epilepsy [26, 29-32]. In our study, serum interictal IL-6 concentration was the only one associated with all seizure severity evaluation scales in all three types of epilepsy. In multivariate analysis, it was positively linked to severity of all three types of epilepsy, indicating that serum IL-6 may be a good candidate to indicate seizure severity in general.

Cytokine levels in CSF are important markers for many different diseases [21]. IL-17a is involved in the development of many inflammatory diseases and has been reported to correlate with disease severity [33]. Another report indicated that interictal serum and CSF IL-17a concentrations were biomarkers for seizure severity [8], which is consistent to our findings. IL-17a is known to be able to facilitate migration of active $\mathrm{T}$ cells, including Th17, across the blood brain barrier [8]. Although, so far, there is no unequivocal proof that $\mathrm{T}$ cells exacerbate seizures directly, they may possibly play roles in the development of seizure indirectly, which could explain why IL-17a was significantly elevated in our study. This theory requires further investigation to proof.

IFN $\lambda$ s are novel cytokines and their roles in seizures have not been well defined yet. We evaluated the serum and CSF level of IFN $\lambda$ s and found that, among 4 IFN $\lambda s$, IFN $\lambda 3$ was associated with seizure severity and the time to next seizure episode (Tables $3,4,5$ ), which 

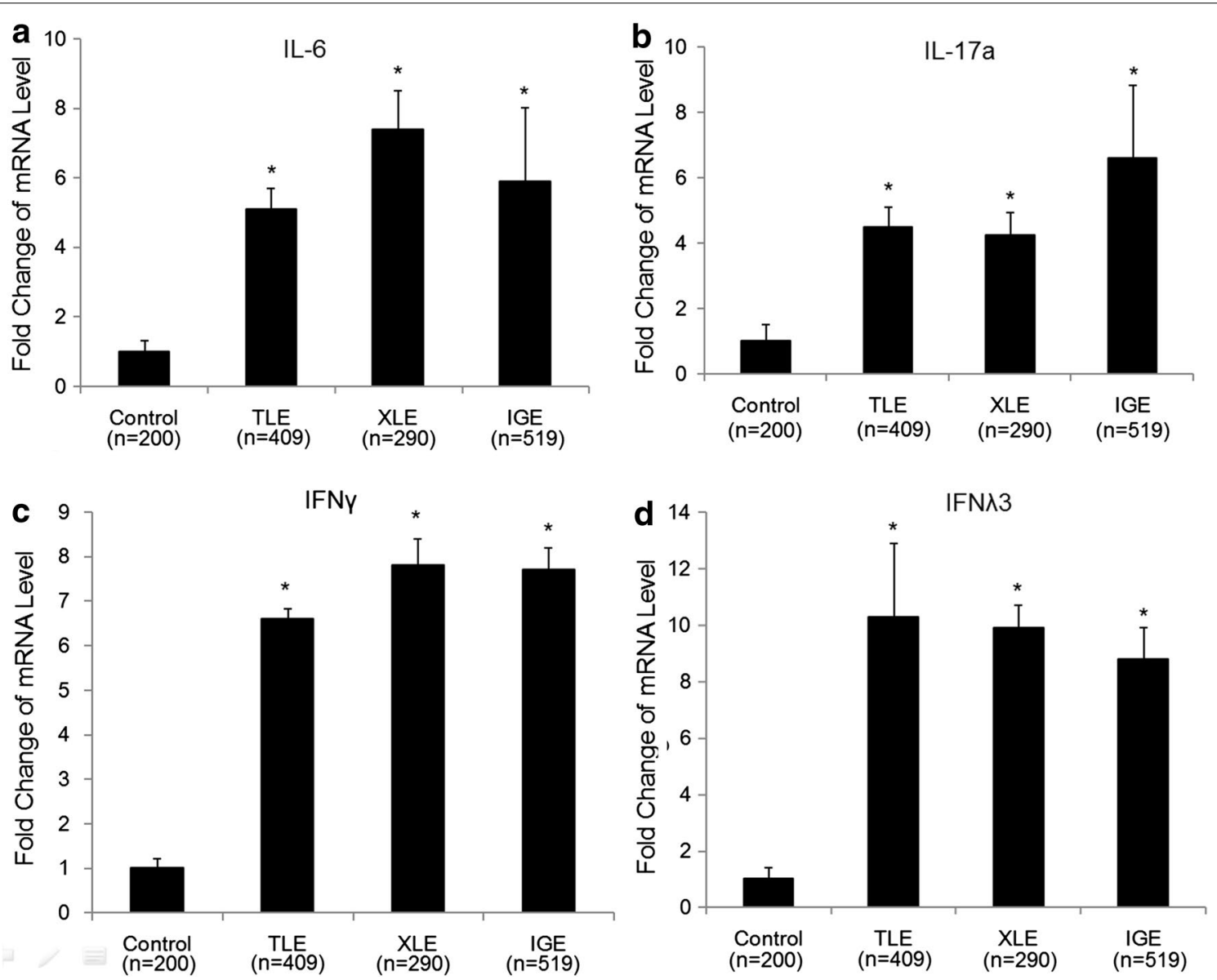

Fig. 2 Serum mRNA concentration of IL-6, IL-17a, IFNy and IFN 3 were elevated in epilepsy. Serum mRNA concentration of IL-6 (a), IL-17a (b), IFNY (c) and IFN 3 (d) were measured in healthy controls and patients with TLE, XLE or IGE. Data represent a minimum of three independent experiments. Asterisks denote $\mathrm{p}<0.05$ in comparison to untreated samples. TLE: temporal lobe epilepsy, XLE extra-temporal lobe epilepsy, IGE idiopathic generalized epilepsy

Table 5 Correlations between interictal cytokine levels and the time to next seizure episode

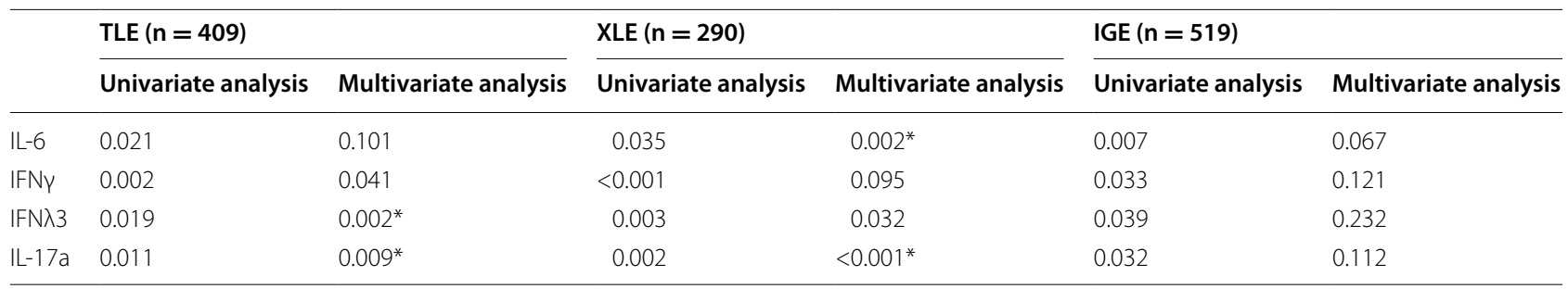

$T L E$ temporal lobe epilepsy, XLE extra-temporal lobe epilepsy, IGE idiopathic generalized epilepsy

${ }^{*} \mathrm{P}<0.01$

was confirmed by mRNA concentration measurement (Fig. 2). This is consistent with previous findings in encephalitis [34].

Other cytokines in our study, such as IL-1b, IL-1Ra, and IL-8, were also correlated to seizure severity in univariate analysis (Table 3 ). IL-1b concentration was reported minimal changed postictally [6]. In our study, it was only correlated to VA score in XLE. Publications have shown that IL-1Ra level changed dramatically during seizure attack [6]. It was linked to seizure severity in all three types of epilepsy. As a pro-inflammatory chemokine, IL- 8 has been reported to be involved in 
Table 6 Interictal CSF IL-6, IL-17a, and IFN $\lambda 3$ levels were independent biomarkers for seizure severity

\begin{tabular}{|c|c|c|c|c|c|c|c|c|c|}
\hline & \multicolumn{3}{|c|}{$\operatorname{TLE}(n=50)$} & \multicolumn{3}{|c|}{$\operatorname{XLE}(n=50)$} & \multicolumn{3}{|c|}{ IGE $(n=50)$} \\
\hline & Freq & VA & NHS3 & Freq & VA & NHS3 & Freq & VA & NHS3 \\
\hline IL-6 & & & & & & $0.007^{*}$ & & & \\
\hline IL-17a & & 0.039 & & & & & & 0.044 & \\
\hline IFN $\lambda 3$ & & & 0.022 & & & & & & 0.012 \\
\hline
\end{tabular}

Freq seizure frequency per month, VA score Veterans Administration Seizures Frequency and Severity Rating Scale score, NHS3 National Hospital Seizure Severity Scale, TLE temporal lobe epilepsy, XLE extra-temporal lobe epilepsy, IGE idiopathic generalized epilepsy

$* P<0.01$
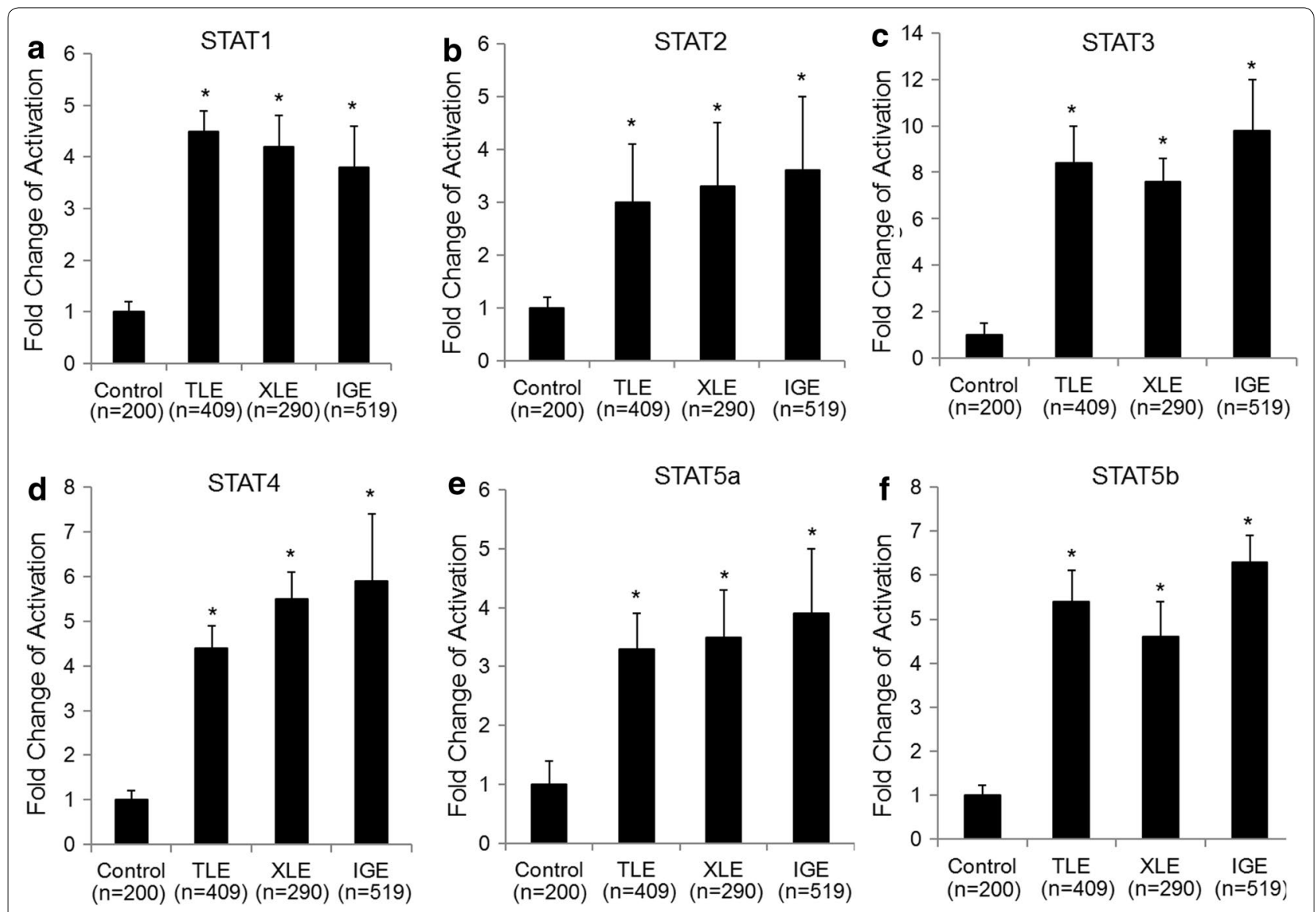

Fig. 3 STATs were activated in patients with different types of epilepsy. PBMCs were extracted from healthy controls and different epileptic patients (TLE, XLE and IGE). Levels of activated STAT1 (a), STAT2 (b), STAT3 (c), STAT4 (d), STAT5a (e), and STAT5b (f) were measured by flow cytometry. Data represent a minimum of three independent experiments. Asterisks denote $p<0.05$ in comparison to untreated samples. TLE temporal lobe epilepsy, XLE extra-temporal lobe epilepsy, IGE idiopathic generalized epilepsy

diseases of respiratory and neurological disorders [3537]. In our study, IL-8 level was associated with seizure severity of all three types of epilepsy. This is consistent with previous publication [7].

\section{Conclusions}

Among 14 cytokines, four independent biomarkers (IL6. IFN $\gamma$, IL-17a and IFN $\lambda 3$ ) for severe seizures in three different types of epilepsy were identified. All STATs were activated in epilepsy, among which, STAT3 was the most activated one. Important roles of these cytokines in the development of severe seizure could be speculated, and they may be used as potential markers to identify severe epilepsy.

\section{Abbreviations}

CSF: cerebrospinal fluid; CNS: central nerve system; IFN: interferon; IL: interleukin; TLE: temporal lobe epilepsy; XLE: extra-temporal lobe epilepsy; 
IGE: idiopathic generalized epilepsy; NHS3: seizure severity scale 3; VA score: veterans administration seizures frequency and severity rating scale score; SD: standard deviation.

\section{Authors' contributions}

YW: collected patient information and blood/CSF samples. DW: collected patient information and performed statistical analysis. DG: conceived of the study participated in the design of the study and drafted the manuscript. All authors read and approved the final manuscript.

\section{Author details}

${ }^{1}$ Department of Neurology, First Affiliated Hospital of Harbin Medical University, Harbin, Heilongjiang 150001, Peoples' Republic of China. ${ }^{2}$ Department of Clinical Laboratory, First Affiliated Hospital of Harbin Medical University, Harbin, Heilongjiang 150001, Peoples' Republic of China.

\section{Competing interests}

The funders had no role in study design, data collection and analysis, decision to publish, or preparation of the manuscript. None of the information in this manuscript has been presented in any meeting or conference. The authors have declared no commercial or other association and have no competing interests.

Received: 20 May 2015 Accepted: 25 November 2015 Published online: 01 December 2015

\section{References}

1. Ban E, Milon G, Prudhomme N, Fillion G, Haour F. Receptors for interleukin-1 (alpha and beta) in mouse brain: mapping and neuronal localization in hippocampus. Neuroscience. 1991;43(1):21-30. doi:10.1016/0306-4522(91)90412-H.

2. Rezaie P, Trillo-Pazos G, Everall IP, Male DK. Expression of beta-chemokines and chemokine receptors in human fetal astrocyte and microglial co-cultures: potential role of chemokines in the developing CNS. Glia. 2002;37(1):64-75. doi:10.1002/glia.1128.

3. Lee YB, Nagai A, Kim SU. Cytokines, chemokines, and cytokine receptors in human microglia. J Neurosci Res. 2002;69(1):94-103. doi:10.1002/ jnr.10253.

4. Choi J, Koh S. Role of brain inflammation in epileptogenesis. Yonsei Med J. 2008;49(1):1-18. doi:10.3349/ymj.2008.49.1.1.

5. Vezzani A, Conti M, De Luigi A, Ravizza T, Moneta D, Marchesi F, et al. Interleukin-1 beta immunoreactivity and microglia are enhanced in the rat hippocampus by focal kainate application: functional evidence for enhancement of electrographic seizures. J Neurosci. 1999;19(12):5054-65.

6. Uludag IF, Bilgin S, Zorlu Y, Tuna G, Kirkali G. Interleukin-6, interleukin-1 beta and interleukin-1 receptor antagonist levels in epileptic seizures. Seizure. 2013;22(6):457-61. doi:10.1016/j.seizure.2013.03.004.

7. Pernhorst K, Herms S, Hoffmann P, Cichon S, Schulz H, Sander T, et al. TLR4, ATF-3 and IL8 inflammation mediator expression correlates with seizure frequency in human epileptic brain tissue. Seizure. 2013;22(8):675-8. doi:10.1016/j.seizure.2013.04.023.

8. Mao LY, Ding J, Peng WF, Ma Y, Zhang YH, Fan W, et al. Interictal interleukin-17A levels are elevated and correlate with seizure severity of epilepsy patients. Epilepsia. 2013;54(9):e142-5. doi:10.1111/epi.12337.

9. Sinha S, Patil SA, Jayalekshmy V, Satishchandra P. Do cytokines have any role in epilepsy? Epilepsy Res. 2008;82(2-3):171-6. doi:10.1016/j. eplepsyres.2008.07.018.

10. Peltola J, Palmio J, Korhonen L, Suhonen J, Miettinen A, Hurme M, et al. Interleukin-6 and interleukin-1 receptor antagonist in cerebrospinal fluid from patients with recent tonic-clonic seizures. Epilepsy Res. 2000;41(3):205-11 (S0920121100001406).

11. Choi J, Nordli DR Jr, Alden TD, DiPatri A Jr, Laux L, Kelley K, et al. Cellular injury and neuroinflammation in children with chronic intractable epilepsy. J Neuroinflammation. 2009;6:38. doi:10.1186/1742-2094-6-38.

12. Krogias C, Hoepner R, Muller A, Schneider-Gold C, Schroder A, Gold R. Successful treatment of anti-Caspr2 syndrome by interleukin 6 receptor blockade through tocilizumab. JAMA Neurol. 2013;70(8):1056-9. doi:10.1001/jamaneurol.2013.143.
13. Sonmez FM, Serin HM, Alver A, Aliyazicioglu R, Cansu A, Can G, et al. Blood levels of cytokines in children with idiopathic partial and generalized epilepsy. Seizure. 2013;22(7):517-21. doi:10.1016/j. seizure.2013.03.014

14. Engel J Jr. ILAE classification of epilepsy syndromes. Epilepsy Res. 2006;70(Suppl 1):S5-10. doi:10.1016/j.eplepsyres.2005.11.014

15. Cramer JA, French J. Quantitative assessment of seizure severity for clinical trials: a review of approaches to seizure components. Epilepsia. 2001;42(1):119-29. doi:10.1046/j.1528-1157.2001.19400.x.

16. Wang W, Li W, Yang $X$, Zhang T, Wang Y, Zhong R, et al. Interleukin-8 is elevated in severe hand, foot, and mouth disease. J Infect Dev Ctries. 2014;8(1):94-100. doi:10.3855/jidc.3542.

17. Wang W, Zhu Y, Wu H, Jiao Y, Van Halm-Lutterodt N, Li W. IL-6 and IFNgamma are elevated in severe mumps cases: a study of 960 mumps patients in China. J Infect Dev Ctries. 2014;8(2):208-14. doi:10.3855/ jidc.3557.

18. Li W, Henderson LJ, Major EO, Al-Harthi L. IFN-gamma mediates enhancement of HIV replication in astrocytes by inducing an antagonist of the beta-catenin pathway (DKK1) in a STAT 3-dependent manner. J Immunol. 2011;186(12):6771-8. doi:10.4049/jimmunol.1100099.

19. Li W, Sun G, Yu Y, Li N, Chen M, Jin R, et al. Increasing occurrence of antimicrobial-resistant hypervirulent (hypermucoviscous) Klebsiella pneumoniae isolates in China. Clin Infect Dis. 2014;58(2):225-32. doi:10.1093/cid/ cit675.

20. Li W, Huang $X$, Tong $H$, Wang $Y$, Zhang T, Wang W, et al. Comparison of the regulation of beta-catenin signaling by type I, type II and type III interferons in hepatocellular carcinoma cells. PLoS One. 2012;7(10):e47040. doi:10.1371/journal.pone.0047040.

21. Yuan L, Liu A, Qiao L, Sheng B, Xu M, Li W, et al. The relationship of CSF and plasma cytokine levels in HIV infected patients with neurocognitive impairment. Biomed Res Int. 2015;2015:506872. doi:10.1155/2015/506872.

22. Li W, Lewis-Antes A, Huang J, Balan M, Kotenko SV. Regulation of apoptosis by type III interferons. Cell Prolif. 2008;41(6):960-79. doi:10.1111/j.1365-2184.2008.00558.x.

23. Vezzani A, French J, Bartfai T, Baram TZ. The role of inflammation in epilepsy. Nat Rev Neurol. 2011;7(1):31-40. doi:10.1038/nrneurol.2010.178.

24. Arisi GM. Nervous and immune systems signals and connections: Cytokines in hippocampus physiology and pathology. Epilepsy Behav. 2014;. doi:10.1016/j.yebeh.2014.01.017.

25. Spangelo BL, Gorospe WC. Role of the cytokines in the neuroendocrine-immune system axis. Front Neuroendocrinol. 1995;16(1):1-22. doi:10.1006/frne.1995.1001.

26. Bauer S, Cepok S, Todorova-Rudolph A, Nowak M, Koller M, Lorenz $R$, et al. Etiology and site of temporal lobe epilepsy influence postictal cytokine release. Epilepsy Res. 2009;86(1):82-8. doi:10.1016/j. eplepsyres.2009.05.009.

27. Woodroofe MN, Sarna GS, Wadhwa M, Hayes GM, Loughlin AJ, Tinker A, et al. Detection of interleukin-1 and interleukin-6 in adult rat brain, following mechanical injury, by in vivo microdialysis: evidence of a role for microglia in cytokine production. J Neuroimmunol. 1991;33(3):227-36.

28. Frei K, Leist TP, Meager A, Gallo P, Leppert D, Zinkernagel RM, et al. Production of $B$ cell stimulatory factor-2 and interferon gamma in the central nervous system during viral meningitis and encephalitis. Evaluation in a murine model infection and in patients. J Exp Med. 1988;168(1):449-53.

29. D’Arcangelo G, Tancredi V, Onofri F, D'Antuono M, Giovedi S, Benfenati F. Interleukin- 6 inhibits neurotransmitter release and the spread of excitation in the rat cerebral cortex. Eur J Neurosci. 2000;12(4):1241-52. doi:10.1046/j.1460-9568.2000.00011.x.

30. Alapirtti T, Rinta S, Hulkkonen J, Makinen R, Keranen T, Peltola J. Interleukin-6, interleukin-1 receptor antagonist and interleukin-1 beta production in patients with focal epilepsy: a video-EEG study. J Neurol Sci. 2009;280(1-2):94-7. doi:10.1016/j.jns.2009.02.355.

31. Lehtimaki KA, Keranen T, Huhtala H, Hurme M, Ollikainen J, Honkaniemi J, et al. Regulation of IL-6 system in cerebrospinal fluid and serum compartments by seizures: the effect of seizure type and duration. J Neuroimmunol. 2004;152(1-2):121-5. doi:10.1016/j.jneuroim.2004.01.024.

32. Lehtimaki KA, Keranen T, Palmio J, Makinen R, Hurme M, Honkaniemi J, et al. Increased plasma levels of cytokines after seizures in localization-related epilepsy. Acta Neurol Scand. 2007;116(4):226-30 doi:10.1111/j.1600-0404.2007.00882.x. 
33. Montes M, Zhang X, Berthelot L, Laplaud DA, Brouard S, Jin J, et al. Oligoclonal myelin-reactive $T$-cell infiltrates derived from multiple sclerosis lesions are enriched in Th17 cells. Clin Immunol. 2009;130(2):133-44. doi:10.1016/j.clim.2008.08.030

34. Grygorczuk S, Parczewski M, Moniuszko A, Swierzbinska R, Kondrusik M, Zajkowska J, et al. Increased concentration of interferon lambda-3, interferon beta and interleukin-10 in the cerebrospinal fluid of patients with tick-borne encephalitis. Cytokine. 2015;71(2):125-31. doi:10.1016/j. cyto.2014.10.001

35. Cassatella MA, Meda L, Bonora S, Ceska M, Constantin G. Interleukin 10 (IL-10) inhibits the release of proinflammatory cytokines from human polymorphonuclear leukocytes. Evidence for an autocrine role of tumor necrosis factor and IL-1 beta in mediating the production of IL-8 triggered by lipopolysaccharide. J Exp Med. 1993;178(6):2207-11.
36. Hirano T. Interleukin 6 and its receptor: 10 years later. Int Rev Immunol. 1998;16(3-4):249-84. doi:10.3109/08830189809042997.

37. Ovsyannikova IG, Jacobson RM, Dhiman N, Vierkant RA, Pankratz VS, Poland GA. Human leukocyte antigen and cytokine receptor gene polymorphisms associated with heterogeneous immune responses to mumps viral vaccine. Pediatrics. 2008;121(5):e1091-9. doi:10.1542/ peds.2007-1575.

\section{Submit your next manuscript to BioMed Central} and we will help you at every step:

- We accept pre-submission inquiries

- Our selector tool helps you to find the most relevant journal

- We provide round the clock customer support

- Convenient online submission

- Thorough peer review

- Inclusion in PubMed and all major indexing services

- Maximum visibility for your research

Submit your manuscript at www.biomedcentral.com/submit
(O) BioMed Central 